(RESEARCH ARTICLE)

\title{
A new tapeworm Stilesia jadhavae sp.nov.from the intestine of goat Capra hircus at Patoda tehsil of Beed district, MS, India
}

\author{
Jadhav Sham Sampatrao ${ }^{1}$ and Lakhe Ashok Devidasrao ${ }^{2, *}$ \\ ${ }^{1}$ Department of Zoology, Baburaoji Adaskar Mahavidyalaya, Kaij, Dist. Beed, M.S., India. \\ 2 Department of Zoology, Arts, Commerce \& Science College Kille Dharur, Dist. Beed, M.S., India. 431124.
}

Publication history: Received on 15 July 2020; revised on 22 July 2020; accepted on 24 July 2020

Article DOI: https://doi.org/10.30574/wjarr.2020.7.1.0266

\begin{abstract}
The present communication deals with the description of a new cestode Stilesia jadhavae sp.nov. from the intestine of goat Capra hircus at Patoda tehsil of Beed district. The examined parasites were long with scolex, immature, mature and gravid proglottids. The scolex of the worm is large, quadrangular, broad anteriorly, narrow posteriorly, distinctly marked off from the strobila; suckers are four, large in size, oval in shape, arranged in two pairs; neck short; mature segments small in size, broader than long having only one set of reproductive organs in each segment; testes 24 in number, medium, round in two lateral fields; cirrus pouch small in size, oval in shape; cirrus is thin coiled; vas deferens thin, small, coiled; ovary medium in size, bilobed; vagina thin coiled; ootype small in size, round in shape; genital pores are small in size, round in shape, regularly alternate; excretory canals narrow.
\end{abstract}

Keywords: Tapeworm; Stilesia jadhavae; Capra hircus; Patoda.

\section{Introduction}

The genus Stilesia was erected by Railliet in 1893, from Ovis aries in Europe, Asia and Africa, as Stilesia globipunctata. Later on S. hepatica was added to this genus by Wolffhugel in 1903 from sheep and goat in East Africa. Stilesia vittata was reported by Railliet in 1896 from Camelus dromedarius from Africa and India. Stilesia okapi is erected as a new species of this genus by Leiper in 1936 from Okapi in Africa, is regarded by Baer, 1950 as a variety of Stilesia globipunctata. The author agrees with Baer to regard Stilesia okapi as S. globipunctata.

Later on the following species are added to this genus by different workers in the world as-1) S. globipunctata (Rivolta, 1874) Railliet, 1893 from Ovis aries. 2) S. vittata Railliet, 1896 from Camelus dromedarius. 3) S. hepatica Wolffhugel, 1903 from Ovis aries. 4) S. okapi, Leiper 1936 from Okapi. 5) S. leiperi, Kadam et al., 1980 from Ovis bharal. 6) S. caballeroi Kalyankar et al., 1981 from Capra hircus. 7) S. southwelli Shinde et al; 1982 from Capra hircus. 8) S. aurangabadensis Jadhav et al., 1982 from Ovis bharal at Aurangabad. 9) S. garhwalensis Malhotra and Capoor, 1983 from Capra hircus. 10) S. kotdwarensis Malhotra and Capoor, 1983 from Ovis bharal. 11) S. marthwadaensis, Shinde et al., 1985 from Capra hircus. 12) S. jadhavae Jadhav, 1999 from Ovis bharal.13) S. yawalensis, Kalse et al., 1999 form Capra hircus. 14) S. dhondagae, Deshmukh and Shinde, (2001) from Capra hircus. 15) S. pandeyi, Nanaware and Jadhav, (2004) from Capra hircus. 16) S. indapurensis, Khadap, et al., (2004) in Capra hircus. 17) S. daulatabadensis, Shelke and Shinde (2004) from Capra hircus. 18\} S. Jadhavi 2005 Nanaware et al., from Capra hirrus.19) Pawar et al.,(2004) Stilesia ambajogaensis from Bos indicus from Ambajogai 20) Sanap,(2016) 21) Lakhe AD (2018) Stilesia shindei, from Ovis bharal 22) Gul-e-lala etal., (2020). Stilesia cribbi sp.nov from goat Capra hircus.

The present species of cestode parasite Stilesia jadhavae sp.nov.is one more addition in the previous record of taxonomy of cestode.

\footnotetext{
* Corresponding author: Lakhe Ashok Devidasrao
} 


\section{Material and methods}

Sixteen specimens of the cestode parasites were collected from the intestine of goat Capra hircus. The collected parasites were long with thin musculature having numerous immature and mature segments. The worms were flattened, preserved in 4\% formalin, stained with Harris haematoxylin, passed through various alcoholic grades, cleared in xylol, mounted in DPX and whole mount slides were taken for further anatomical studies. The drawings were made with the aid of Camera Lucida and all measurements in millimeters.

\subsection{Description}

The scolex of the worm is fairly large in size, quadrangular in shape, broader anteriorly, narrow posteriorly, marked off from the strobila and measures 0.834-1.182 in length and 0.530-1.349 in breadth. The suckers are four in number, large in size, oval in shape, arranged in two pairs, attached to each other, touching lateral margins of the scolex and measures 0.341-0.409 in length and 0.326-0.432 in breadth. The neck is short, median in width, slightly broad anteriorly and measures 0.189-0.258 in length and 0.417-0.523 in breadth. The mature segments are small in size, very thin, broader than long, having only one set of reproductive organs in each segment, lateral margins are convex and measures 0.197 0.242 in length and 1.592-1.614 in breadth. The testes are 23-29 (24) in number, medium, round, in two lateral fields of the segment and measures 0.015-0.038 in diameter. Cirrus pouch small, oval, elongated, transversely placed, anteriorly directed, extending up to the longitudinal excretory canals and measures 0.045 in length and 0.023-0.030 in breadth. Cirrus thin, coiled, contained within the cirrus pouch and measures 0.053 in length and 0.008 in breadth. Vas deferens thin, small, coiled, runs transversely, anteriorly directed and measures 0.144 in length and 0.008 in breadth. Ovary medium in size, bilobed, oval with irregular margins and measures 0.068-0.083 in length and 0.038-0.053 in breadth. Vagina is thin, coiled, posterior to cirrus pouch and measures 0.197 in length and 0.008-0.015 in breadth. Ootype small in size, round in shape and measures 0.015 in diameter. Vitelline glands absent. The genital pores are small in size, round in shape, irregularly alternate, situated just anterior to middle of the segments and measures 0.015 in diameter. The longitudinal excretory canals are narrow and measures 0.023 in breadth.

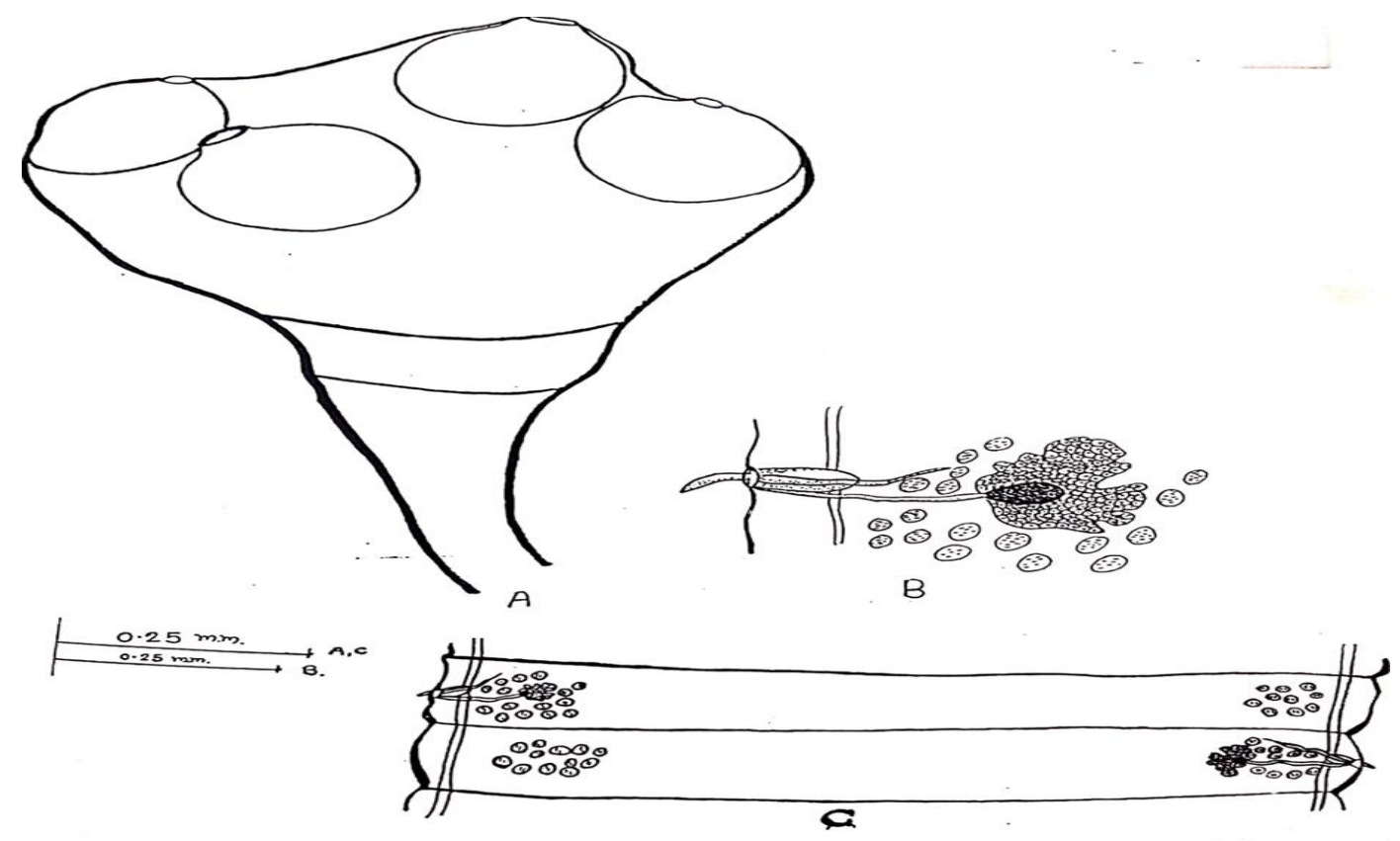

Figure1 Stilesia jadhavae sp.nov. A- Scolex; B- Magnified Reproductive Organ; C-Mature Segment

\section{Results and discussion}

The present communication deals with the description of new species Stilesia jadhavae sp.nov. After going through the literature the worm under discussion differs from the all known species.

- The present worm under discussion differs from Stilesia globipunctata, Railliet (1893)[1],in having the mature proglottid broader than long, with distinct segmentation; testes in two groups,4-7 on each side; vas deferens not closely coiled between cirrus pouch and outer wall of excretory canal; cirrus pouch small, pyriform, ventral 
to vagina; ovary globular, median; vagina dorsal to cirrus pouch, uterus globular, par uterine organs develops from uterus.

- The present cestode differs from Stilesia vittata, Railliet (1896)[2], which is having mature segments broader than long, with indistinct segmentation; testes in two groups,5-9 on each side; vas deferens closely coiled; cirrus pouch elongated, cylindrical, cirrus armed; ovary rounded, situated between portal vessels; vagina posterior to cirrus pouch, uterus transverse, a large tube near the anterior margin; par uterine organs two in number, in each segment, big, developed from uterus and internal to the excretory vessels.

- The present form differs from Stilesia hepatica,Wolffhugel (1903)[3],in having the mature segments broader than long, craspedote, testes in two groups,6-7 on each side, pre ovarian, in anterior half of the segments; vas deferens not closely coiled, but extends up to longitudinal excretory vessels; cirrus pouch almost oval, ovary small, compact, oval; vagina anterior to the cirrus pouch, uterus a transverse and small tube, in the centre; par uterine organ situated internal to the longitudinal excretory vessel.

- The present tapeworm differs from Stilesia leiperi Kadam et.al.,(1980)[4], which is having the mature segments broader than long, testes in two groups,5-6 on each side, postero lateral to ovary; vas deferens not closely coiled, but extends beyond the longitudinal excretory canals; cirrus pouch elongated, cylindrical; ovary medium, almost circular, compact, with small acini; vagina posterior to cirrus pouch, uterus a broader transverse tube, in the anterior half of the segment, with two lateral sacs, having par uterine organs, at distal end and develops from uterus, situated in between dorsal and ventral excretory canals.

- The present worm, differs from Stilesia caballeroi Kalyankar et.al.,(1981)[5], in having the testes 1-11 on each side, vas deferens forms a less dense bundle of convolutions, anterior to the testes; cirrus pouch oval, vagina opens into the genital cloaca, posterior to the cirrus pouch and the par uterine organs spherical on postero lateral surface.

- The present cestode differs from Stilesia southwelli Shinde et.al.,(1982)[6], in having mature segments much broader than long, in two groups; vas deferens very much coiled, reaching up to ovary; cirrus pouch large, sac like; ovary medium, almost round, compact, without acini, in the centre of the segments; vagina posterior to the cirrus pouch, uterus secular, a thin transverse tube and two par uterine organs in each gravid segment, which are large, oval, containing 10-15 eggs.

- The present tapeworm differs from Stilesia aurangabadensis, Majjid et.al.,(1982)[7], in having mature segments much more broader than long; testes in two lateral groups, round 5 on each side; vas deferens straight reaches to the longitudinal excretory canals; cirrus pouch elongated, cylindrical; cirrus coiled; ovary medium, circular compact; vagina a thin tube and postero dorsal to cirrus pouch.

- The present worm differs from Stilesia garhwalensis Malhotra and Capoor (1983)[8], in having mature segments broader than long, testes 0-9 in number, on each side, oval to spherical; cirrus pouch oval, extending half way between lateral margin and longitudinal excretory canal; ovary small, spherical, vas deferens coiled, par uterine organs two in number, one on each lateral side of the segment.

- The present tapeworm, differs from Stilesia kotdwarensis, Malhotra and Capoor (1983)[8], in having the mature segment broader than long, testes oval to spherical,1-2 in number, on each side, the number varies from segment to segment, maximum 6 on each side; vas deferens coiled, reaches up to the longitudinal excretory canals; cirrus pouch oval, extending half across between lateral margins and ventral to longitudinal excretory canal; ovary small, spherical; vagina posterior to the cirrus pouch; par uterine organs small, between dorsal and ventral longitudinal excretory canals, two in each gravid segment.

- The present form differs from Stilesia marathwadaensis Shinde et.al., (1985)[9], in having the mature segments broader than long, testes round, in two groups, 5-7 in number, postero lateral to ovary; vas deferens not coiled, cirrus pouch oval, elongated, cylindrical, present at the anterior margin of segment; ovary medium in size, oval in shape, compact in anterior half of the segments; vagina on the posterior side of the cirrus pouch, par uterine organs two in number, oval in shape, large in size.

- The present worm differs from Stilesia jadhavae, Jadhav (1999)[10], in having large ovary as compared to the present worm.

- The worm under discussion differs from Stilesia yavalensis Shinde and Kalse (1999)[11], which has quadrangular scolex and from Stilesia dhondagae Deshmukh et.al., (2001) in having quadrangular scolex and testes 8-10 in number, arranged in two rows, vas deferens short. 
- The present worm differs from Stilesia capari Patil and Menkudle (2002)[12], in having vas deferens short and ovary sac like.

- The present form differs from Stilesia pandeyi Nanware et al., (2004)[13], in number of testes and shape of ovary.

- The present cestode differs from Stilesia indapurensis Khadap (2004)[14], in having vas deferens curved; It also differs from Stilesia daulatabadensis Shelke and Shinde (2004) in having acraspedote testes and vas deferens slightly curved.

- The present cestode parasite differs from Stilasia ambajogaensis Pawar et.al. (2004)[15], in having mature segments broader than long; testes 25-30 (28) medium, oval, arranged in three fields, in two lateral groups in the central medulla, third group having three testes in each segment, outside the longitudinal excretory canals, vas deferens short, thin tube; cirrus pouch medium long; ovary small, oval, a single mass; vagina thin, medium, curved, posterior to the cirrus pouch; genital pore small, oval, regularly alternate.

- It also differs from Stilesia jadhavi Nanware and Jadhav (2005)[16], in having testes 14 in number and ovary bilobed.

- The present worm differs from Stilesia govindae Padwal and Jadhav (2006)[17], which has ovary lobulated and testes12-14 in number and also from Stilesia kanegaonensis Patil (2012) in having vas deferens short and ovary divided into two pairs.

- The present cestode differs from Stilesia shindei Lakhe (2018)[18], in having the mature segments squarish, broader than long, almost 16 times broader than long; testes medium, oval, 11-14 in number, $5+6$ or $6+8$ in each segment; ovary medium, oval, single mass, compact.

- The present tapeworm differs from Stilesia cribbi Gule-e-Lala et.al.(2020)[19], in having scolex globular, roughly rounded; neck small; mature segments wide; testes small globular 6-8 in number; cirrus pouch small; cirrus long; vas deferens long; ovary large, globular.

\subsection{Taxonomic summary}

- Genus : Stilesia Railliet, 1893

- Species : Stilesia jadhavae sp.nov.

- Host : Capra hircus

- Habitat : Intestine

- Locality $\quad$ : At. Patoda Tq. Patoda, Dist. Beed, M.S., India.

- Date of Collection : $5^{\text {th }}$ May 2019

- Etymology : The name of the species is proposed after the author's father surname.

\section{Conclusion}

The above noted characters are valid enough to erect a new species Stilesia jadhavae sp.nov. Hence the name of the species is proposed after the author's father surname.

\section{Compliance with ethical standards}

\section{Acknowledgments}

Both authors are very much thankful to the Principal Arts, Commerce and Science College Kille Dharur, Dist. Beed, MS, for providing the research facility in the Research Centre, Department of Zoology of the college.

\section{Disclosure of conflict of interest}

All authors declare no conflict of interest is exist. 


\section{References}

[1] Railliet. (1893). (Anoplocephalidae, Cestoda) from a goat, Capra hircus (L) at Aurangabad. Journal of Biological Research, 2, 51-57.

[2] Railliet A. (1896). Sur quelques parasites du Dromadaire. Comptes Rend. Societe de Biologie Paris.Vol. XLVIII, 489-492.

[3] Wolffhugel K. (1903). Stilesia hepatica nov.sp. in Band Wurmans den Gallengangen Von Schafen und ZiegenOstafrikaskanNerlin. TierarztWochenscher, 43, 661-665.

[4] Kadam SS,Shinde GB and Jadhav BV. (1980). On a new species of Stilesia, Railliet 1893 (Cestode: Thysanosomatinae) Skrjabin, 1933 from sheep at Aurangabad. Journal of Biological Research, 2, 33-36.

[5] Kalyankar SD, Deshmukh AL and Hatwalkar VM. (1981). A new species of genus Stilesia.

[6] Shinde GB, Kadam SS and Jadhav BV. (1982). On a new cestode Stilesia southwelli n.sp. from goat at Aurangabad, India. Marathwada University Journal of Sciences, 49-53.

[7] Majjid MA, Shinde GB and Jadhav BV. (1982). Marath.Univ.J.of Sci. (Nat.Sci.), 21(14), 37-39.

[8] Malhotra SK and LN Cappor. (1983). On two new species of cestode (Cyclophyllidea), Stilesia garhwalensis n.sp. from goat and Stilesia kotdwarensis n.sp. from sheep of the Garwal region, India. Acta Parasitologica, 28, $399-406$.

[9] Shinde GB, Jadhav BV and Phad AN. (1985). Stilesia marathwadaensis n.sp. (Cestoda: Thysanosomidae) from Capra hircus at Aurangabad. Rivista di Parassitologia, 2, 213-215.

[10] Jadhav BV. (1999). The new species of tapeworm Stilesia jadhavae n.sp. from Ovis bharal at Aurangabad, Rahavard Henderson Centre 1998, pp. Abstract 3. Scientific Journal of the Union of the Iranian student Islamic Association, India, 1.

[11] Shinde GB and Kalse AT. (1999). On a new tapeworm Stilesia yavalensis (Cestoda: Thysanosomidae, Fuhrmann, 1907) sp. nov.from Capra hircus in India. Uttar Pradesh Journal of Zoology, 19, 89-91.

[12] Patil DP and Menkudle DV. (2002). Stilesia capari n.sp. from Capra hircus (Goat) at Surpur (Karnatka) India. Utter Pardesh Journal of Zoology, 255-258.

[13] Nanware S, Jadhav B and Vinod G. (2004). On a new cestode Stilesia pandeyi sp. nov. (Cestoda: Thysanosomidae) from Capra hircus (L.) India. Journal of Helminthology, 22, 9-14.

[14] Khadap RM. (2004). A new species of the genus Stilesia indapurensis n.sp. from Capra hircus at Indapur, Pune, India. Journal of Comapartive Toxicology and Physiology, 1, 249-252.

[15] Pawar SB, Lakhe AD,Shinde GB and Patil AS. (2004). A new cestode Stilesia ambajogaensis n.sp. Eucestoda Thysanosomi from Bos indicus at Ambajogai, M.S. India. Rivista di Parasitologia, 212, 81-85.

[16] Nanware S and Jadhav B. (2005). Taxanometric evaluation of a new mammalian cestode Stilesia, Railliet 1893 (Cestoda: Thysanosomidae) infecting Capra hircus (L.). National Journal of Life Sciences, 2, 393-397.

[17] Padwal N and Jadhav B. (2006). Stilesia govindae n.sp. (Cestoda: Thysanosomatinae, Fuhramann, 1907) from Ovis bharal. National Journal of Life Sciences, 3, 309-312.

[18] Lakhe AD, (2018). A new species of cestode parasite Stilesia shindei, from Ovis bharal at Parli V. Life Science bulletin, 15(1), 59-61.

[19] Gul-e-lala et.al. (2020). On a new tapeworm Stilesia cribbi sp.nov. (Cestoda: Thysanosomodae. Fuhrman,1907) from Goat (Capra hircus) in Pakistan. Int. J. Biol. Bioh, 17(1), 121-124.

\section{How to cite this article}

Jadhav SS and Lakhe AD. (2020). A new tapeworm Stilesia jadhavae sp. nov. from the intestine of goat Capra hircus at Patoda tehsil of Beed district, MS, India. World Journal of Advanced Research and Reviews, 7(1), 222-226. 